\title{
Feasibility of producing biodegradable disposable paper cup from pineapple peels, orange peels and Mauritian hemp leaves with beeswax coating
}

\author{
Swabiiha Buxoo ${ }^{1}$ Pratima Jeetah ${ }^{1}$ iD
}

Received: 14 March 2020 / Accepted: 1 July 2020 / Published online: 9 July 2020

(c) Springer Nature Switzerland AG 2020

\begin{abstract}
While past studies have been carried out to form eco-friendly disposable tableware using non-wood biomass, there is no present groundwork so far where fruit peels waste composited with Mauritian hemp (Furcraea foetida) has been used for such purpose, which is novel to this research work. This study therefore assesses whether the production of $100 \%$ biodegradable disposable paper cups with acceptable strength properties using pineapple (Ananas comosus) peels, orange (Citrus sinensis) peels and Mauritian hemp as feedstock is feasible. Soda pulping followed by vacuum molding was done to produce hemp:pineapple peels and hemp:orange peels composite paper cups in different ratios. The cups were tested using relevant standards in terms of appearance and structure, burst strength, tensile strength, weight load, water leakage and biodegradability to find the optimum cup composition by comparing with a suitable control. All cups were visually conformant in terms of color and base stability. The 40:60 hemp-pineapple peels composite cup had characteristics closest to the control, with no cracks and variation rate of weight load, average thickness of $1.42 \mathrm{~mm}$ and burst and tensile indexes of $0.25 \mathrm{kPa} \mathrm{m} / \mathrm{g}$ and $3.30 \mathrm{Nm} / \mathrm{g}$, respectively. Beeswax coating thickness of $0.70 \mathrm{~mm}$ on the optimum cup was adequate to retain cold water for $30 \mathrm{~min}$ (minimum) without any leakage. The cup also biodegraded completely in both active soil and damp sand environments within 5 and 6 weeks, respectively. Results therefore reveal that fiber extraction from fruit peel wastes and hemp leaves to produce eco-friendly, biodegradable disposable paper cups is viable.
\end{abstract}

Keywords Waste fruit peels fiber · Non-wood lignocellulosic biomass · Biodegradable disposable paper cup · Physical properties · Beeswax waterproof coating · Water holding capacity

\footnotetext{
Statement of Novelty: This is a novel research work, which demonstrates that good quality and low-cost paper cups can be produced from peels of fruit waste and hemp which would have otherwise added stress to the landfill. So far, no research has been carried out on the use of fruit waste for paper cup production. The hemp is a form of agricultural waste which is normally discarded, and in this paper, it is being converted into something useful that can divert the use of virgin wood for paper cup production. Thus, we are in a way managing waste from biomass and adopting a recycling and reuse strategy. Moreover, we are valorizing the biomass which is considered as waste.
}

Pratima Jeetah, p.jeetah@uom.ac.mu|'Department of Chemical and Environmental Engineering, University of Mauritius, Reduit, Mauritius. 


\section{Introduction}

Today's hectic lifestyle coupled with the emerging trend of takeaway services in the fast food and beverage industries has influenced the growth of disposable tableware market across the globe [1]. While one-time use cups, bowls, plates, cutlery, among others, have become a must-have convenience object, the conventional material from which they are made of negatively impacts the natural environment. Disposable tableware is commercially manufactured using polystyrene, polypropylene or polyethylene, which are obtained from the non-renewable petroleum source. These synthetic plastic materials are resistant to natural degradation, as a result of which they accumulate in the environment and landfills after disposal. The accumulated plastics in the environment take years to fragment to microplastics and nanoplastics, which are more dangerous to the human health as well as land and aquatic life because of their small particle size [2].

Disposable tableware is also commercially manufactured using paper material obtained from virgin wood pulp and thereafter coated with polyethylene, which is a non-biodegradable petrochemical product tightly bonded to the paper to make the product waterproof and therefore able to contain liquid. With increasing consumer demands, massive deforestation is occurring to make paper tableware, which is in turn contributing to climate change, loss of biodiversity, disruption in the natural water cycle, soil erosion, among others. The difficulty of recycling these products is increased by the fact that they are contaminated with drinks. This means that the paper tableware cannot be recycled at standard recycling plants and must instead be taken to special facilities to separate the paper from the plastic lining [3]. The polyethylene coating therefore retards the biodegradation of paper containers and reduces their recyclability potential when contaminated with drinks, and given the increasing production of the one-time use paper tableware, there would be a higher amount of these reaching the landfill as waste since they cannot be composted, recycled or biodegraded.

As such, research interests have been diverted toward the use of sustainable non-wood sources for bioplastic and paper tableware production in recent years as a potential solution. The cellulose from sustainable sources such as agro-waste, industrial by-products and renewable non-wood crops can be used for both bioplastic and paper production. However, it is often used for paper products mostly since approximately $50 \%$ of the bioplastics used commercially are prepared from starch [4,5]. Pavlovskay et al. [6] attempted to produce bioplastic composites using nongraded wheat grains and hydrolyzed sugar beet pulp to produce disposable tableware based on starch. Although all-starch tableware possesses advantages such as completing degradation and high food security, its low thermal stability, high flexibility, difficulty in preservation and high price make it unfavored in market [7]. Some bioplastics, on their own, lack the mechanical properties needed to meet the strength requirements of daily use disposable tableware. Pavlovskay et al. [6] then added the synthetic polyethylene glycol to the composite for added strength, which thereafter makes it only partially biodegradable.

Hence, while much research has been done in developing bioplastic, such as the study conducted by Marichelvam et al. [4] to produce a corn and rice-starch-based bioplastic with glycerol, citric acid and gelatin as plasticizers to increase the tensile strength, they have mostly been developed for packaging applications $[2,4]$. In addition, although some bioplastics have shown excellent physicochemical, mechanical and degradable properties in many industrial applications, they are currently not a substitute for conventional plastics [2]. Furthermore, bioplastics used for disposable products need to have a faster degradation speed. However, biodegradation of bioplastics needs controlled environmental conditions $[2,5,8]$. Consequently, in the absence of the necessary conditions for biodegradation, the bioplastics have a long degradation phase and can have non-completing degradation [7].

Thus, non-wood fibers for paper tableware production is the direction of this study because of its recyclable, degradable and reusable characteristics [7]. Several studies have been carried out to use cellulosic fibers as molded pulp products to form biodegradable disposable tableware. Curling et al. [9] assessed the feasibility of replacing paper fiber with waste cereal straw fiber by forming flat, round trays, such as those used in supporting shrink wrapped food items. Gouw et al. [10] used apple pomace as a source of alternative fibers and cellulose nanofiber, with the addition of chemicals, as reinforcement agent to create molded pulp packaging boards. Liu et al. [7] studied the possibility of disposable plate production using withered leaves as raw material, while Hanley et al. [8] mixed chopped hemp pieces with agar and corn-starch to make disposable cups. These aforementioned studies, however, use additives, chemicals and bioplastic materials as composites with the cellulosic fibers to produce tableware. It is therefore desirable to produce degradable disposable tableware using minimum to no additives or fillers since the use of synthetic chemicals as well as the cost of raw material needed would be reduced.

Molded pulp products made from pineapple peels, orange peels and the Mauritian hemp as non-wood lignocellulosic biomass have not been studied so far and 
were therefore selected as feedstock. These biomasses, otherwise wastes, are biodegradable and have a small fiber percent that can be used to produce disposable biodegradable paper cups. The Mauritian hemp leaves used as composite material is a non-food crop that grows by itself in all parts of Mauritius. Thus, this research helps in managing and valorizing waste from biomass while promoting a recycling and reuse strategy.

This study therefore attempts to produce a $100 \%$ biodegradable paper cup of acceptable mechanical properties from fruit peels waste and Mauritian hemp without the use of any such additives and/or bioplastic material as waterproof coating. The main aim of this project was to assess the feasibility of biodegradable disposable paper cup production from orange peels and pineapple peels using hemp leaves as composite feedstock. The principle objectives developed to achieve this aim were to investigate the viability of fiber extraction from orange peels, pineapple peels and Mauritian hemp leaves by chemical means, to produce paper cups from composite mixtures of orange and pineapple peels with Mauritian hemp leaves, respectively, to assess and evaluate the properties and service performance of the different paper cups produced by performing physical, chemical and mechanical tests, to compare the properties and service performance of the paper cups produced with a suitable control in view of obtaining the most suitable cup composition and to analyze the biodegradability potential of the most suitable cup composition.

\section{Materials and methods}

\subsection{Material collection and preparation}

All raw materials were locally obtained in the different regions of Mauritius. Fresh pineapple peels waste was obtained from a pickle seller at Chemin Grenier. Fresh orange peels waste was collected from the Gymkhana Club situated in Vacoas, while fresh Mauritian hemp leaves were obtained from the hemp plants found on Candos Hill. The collected biomasses were cut to $2-3 \mathrm{~cm}$ pieces and thereafter washed thoroughly with water to remove dirt and soil particles. The washed fruit peels and hemp leaves were allowed to dry naturally for $24 \mathrm{~h}$, following which they were dried in an oven at $60^{\circ} \mathrm{C}$ until they were moisture free. The hemp leaves were further processed by grinding and sieving them through a $1.17 \mathrm{~mm}$ sieve to obtain a more uniform paste for the cup molding process. All samples were then stored in their respective air-tight plastic bags to prevent moisture re-absorption.

\subsection{Physicochemical characterization of lignocellulosic feedstock}

The biomasses were characterized in terms of moisture, ash, cellulose, hemicellulose and lignin content. The percentage of moisture present in the orange peels, pineapple peels and hemp leaves was determined using the oven-drying method specified in the ASTM E 1756-08 (2015) standard [11] by allowing a known mass of sample to dry to constant mass in an oven at a temperature of $105 \pm 3^{\circ} \mathrm{C}$. The ash content was determined as per the ASTM E 1755-01 (2015) standard [12] by placing 3-5 $\mathrm{g}$ of the shredded sample in a crucible of predetermined weight to incinerate in a Carbolite muffle furnace at a set temperature of $575 \pm 25^{\circ} \mathrm{C}$ for $3 \mathrm{~h}$. Finally, the cellulose, hemicellulose and lignin content determination was based on the acid and neutral detergent solution method developed by Soest [13] and Soest and Wine [14], which consists of three main steps, namely NDF (neutral detergent fiber) determination, ADF (acid detergent fiber) determination and ADL (acid detergent lignin) determination.

\subsection{Pulping process}

Soda pulping was carried out as per the method and conditions described by Sibaly and Jeetah [15] to obtain the dry cellulosic pulp required for the paper cup-making process. Briefly, around $200 \mathrm{~g}$ of biomass was submerged in $2000 \mathrm{~mL}$ aqueous sodium hydroxide solution, which was subsequently heated to a constant temperature of $90 \pm 2.5^{\circ} \mathrm{C}$ for 90 min under atmospheric pressure for pulping to occur, with manual mixing at regular intervals for homogenous delignification. After the cooking process, the beaker and its contents were allowed to cool to room temperature. The cooled cooked mixture was then filtered using cheesecloth as filtering medium such that the black liquor was allowed to be filtrated, while the solid pulp residue was retained. The residue was meticulously washed with hot water (to increase imbibition) until the effluent became clear, with a measured $\mathrm{pH}$ of nearly 7 . The washed pulp was manually inspected and screened to remove any dirt, undigested fibers, shives and knots that might have been present. Finally, the resulting pulp was oven-dried to constant mass at $60^{\circ} \mathrm{C}$ for $24 \mathrm{~h}$. The same $\mathrm{NaOH}$ concentration $(15 \% \mathrm{w} / \mathrm{v})$ as in the reference method was used for hemp leaves and orange peels. For pineapple peels, however, $10 \% \mathrm{w} / \mathrm{v} \mathrm{NaOH}$ was used since it was sufficient for proper delignification to occur. 


\subsection{Cup molding process}

\subsubsection{Cup mold design}

A laboratory-scale vacuum molding setup was manually assembled for the vacuum molding process to occur in the shape of a cup. The cup mold design involved drilling equally spaced $0.5 \mathrm{~mm}$ holes on a rigid high-density polyethylene (HDPE) plastic cup, the mouth of which was then covered and glued with a rigid HDPE cover. The cover was then drilled in the middle to allow an opening for piping connections. A flexible plastic pipe was then connected to the opening using bolts and nuts. A negative pressure gauge was also connected to know the amount of suction pressure being applied. The dimensions of the base and surface of the cup were drawn on a nylon sieve cloth, which were then cut and sewn into the shape of the HDPE cup. The sieve cloth was placed on the perforated HDPE cup, and the whole assembly was connected to the vacuum pump to complete the vacuum cup molding setup.

\subsubsection{Vacuum molding}

The dry pulp of each biomass was weighed in appropriate ratios to a total mass of $15 \mathrm{~g}$ and thereafter blended in around $200 \mathrm{~mL}$ distilled water to form a uniform pulp slurry, which was then applied manually on the mold until it was found to be of satisfactory and even thickness throughout. The applied pulp was then covered using shrink wrap and the vacuum pump created suction at a pressure of 0.05 bars to remove water, causing the pulp to settle and bind together in the form of the cup. The molded pulp together with the sieve cloth was then removed from the HDPE cup and oven-dried to constant mass, after which the formed paper cup was unmolded from the rigid cloth. The formed paper cups were then used for further physical and mechanical tests in order to find the ultimate cup composition for waterproof coating.

\subsection{Waterproof coating}

In order to hold water for drinking purposes, a beeswax coating was applied to the cup having the best mix ratio of hemp-peels. The beeswax was first melted in a beaker, which was placed in a water bath on a hot plate, at a temperature of around 60 to $63^{\circ} \mathrm{C}$. The melted wax was then applied using a small silicone brush. Since the wax solidified as soon as it contacted with the surface of the cup (which was at room temperature), the wax coating was uneven. A hair dryer was then used to blow hot air, which melted the wax again and hence causing it to be distributed uniformly throughout the cup.

\subsection{Physical and mechanical tests}

The appearance and structure test, drop test, weight load test and water leakage test were performed as per the GB 18006 (2008) standard [16]. The burst strength and tensile strength tests of the cups were carried out using the TAPPI T403 OM-97 [17] and TAPPI T494 OM-06 [18] standards, respectively. For the assessment of the biodegradability potential of the cups, the methods described by Tosin et al. [19] and Rosario and Dell [20] were used to analyze the loss in mass of the cup samples in eulittoral zone (damp sand) and active soil, respectively. All physical and mechanical tests were carried out in the order given by the flowchart in Fig. 1 to determine the ultimate cup composition.

\section{Results and discussion}

\subsection{Physicochemical characterization of raw biomass}

The raw materials used for paper cup forming were characterized in terms of dry matter (total dry solids \%), moisture, ash, lignin, cellulose and hemicellulose contents as given in Table 1.

Fig. 1 Cup mold setup

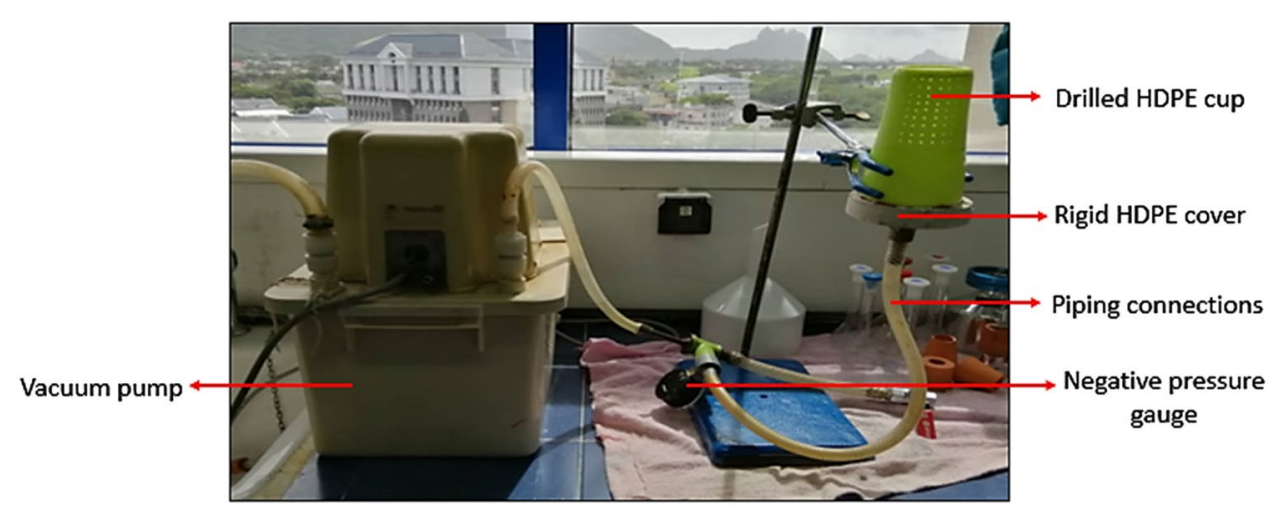


Table 1 Physicochemical properties of raw biomass used

\begin{tabular}{lccc}
\hline (\%) & Pineapple peels & Orange peels & Mauritian hemp leaves \\
\hline Total dry solids & $15.28 \pm 1.14$ & $25.43 \pm 0.21$ & $13.99 \pm 0.63$ \\
Moisture & $84.72 \pm 1.14$ & $74.57 \pm 0.21$ & $86.01 \pm 0.63$ \\
Ash & $7.03 \pm 0.66$ & $3.76 \pm 0.54$ & $5.73 \pm 1.03$ \\
Lignin & $9.21 \pm 1.12$ & $2.65 \pm 0.70$ & $10.99 \pm 1.77$ \\
Cellulose & $36.41 \pm 1.40$ & $10.33 \pm 1.12$ & $69.50 \pm 1.63$ \\
Hemicellulose & $26.19 \pm 1.48$ & $13.18 \pm 1.96$ & $18.71 \pm 2.42$ \\
\hline
\end{tabular}

The Mauritian hemp had the highest moisture content in comparison with pineapple and orange peels. This might be because the hemp leaves also contain a sticky, irritating saponins-containing juice present in the sap (which causes foaming) besides moisture in the plant cell structure [21].

Hemp leaves were also observed to have the highest cellulose content, followed by the pineapple peels. Thus, pulp yield from hemp leaves would be greater since more cellulosic fibers can be recuperated. Higher cellulose content also contributes to the fibers having higher tensile strength [22], which are desirable properties for paper cups. In addition, hemp leaves fiber is longer than that of pineapple peels and orange peels, thereby contributing further to its tensile properties. On the other hand, pineapple peels, with a higher cellulose content than orange peels, have a higher pulp yield and better tensile properties than the latter.

Pineapple peels were found to contain the highest amount of hemicellulose as compared to orange peels and hemp leaves. Despite a higher hemicellulose content indicates that the fiber is highly amorphous with reduced fiber strength [22], it was observed that orange peels contained more hemicellulose than cellulose, while pineapple peels and hemp leaves contained more cellulose than hemicellulose. In this respect, orange peels fiber was inferred to have the lowest fiber strength and mechanical properties, while hemp leaves fibers were considered to have the highest one. Since hemicellulose are easily degraded at high alkali charges, they are easily dissolved away during soda pulping, as a result of which the pulp yield is lower for biomasses having high hemicellulose content.

To produce high-grade paper cups, the lignin content, which is an undesirable polymer in paper making, should be as low as possible [23]. Its removal during pulping requires high amounts of chemicals and energy [24]. In addition, a higher lignin content implies that the cellulosic fibers are bonded more tightly together [25]. This indicates, therefore, that it is more difficult, energy intensive and costly to remove lignin from hemp leaves than from the fruit peels.

\subsection{Appearance and structure test}

Visual inspection of the formed cups is an important step to check for conformity according to GB 18006 (2008) [16]. It gives quality assurance of the product in terms of service performance. In this respect, the color, edge, stability of cup base, texture and cracks were analyzed. The molded paper cups in different ratios are shown in Figs. 2 and 3.

The color, edge and stability of the cup sample and the presence of grease/dirt/dust on its surface were qualitatively analyzed and reported as shown in Table 2.

For the inspection of texture and cracks of the paper cups, scores were assigned as given in Table 3 in order to quantitatively compare the different cup compositions.

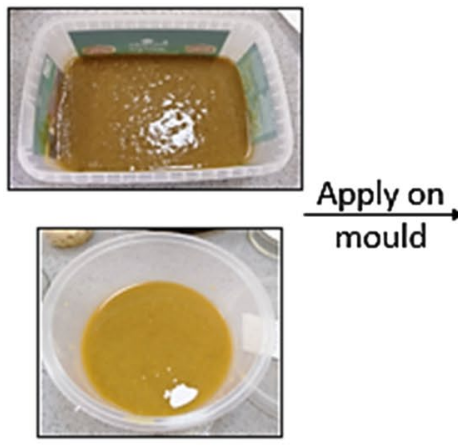

Blended pulp slurry

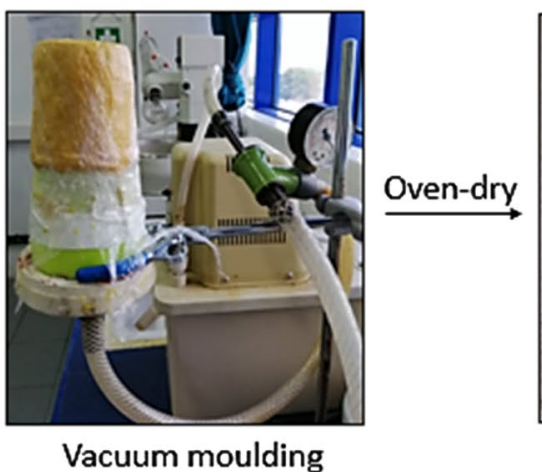

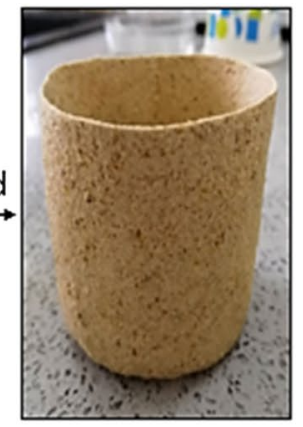

Fig. 2 Molded paper cup-making process 


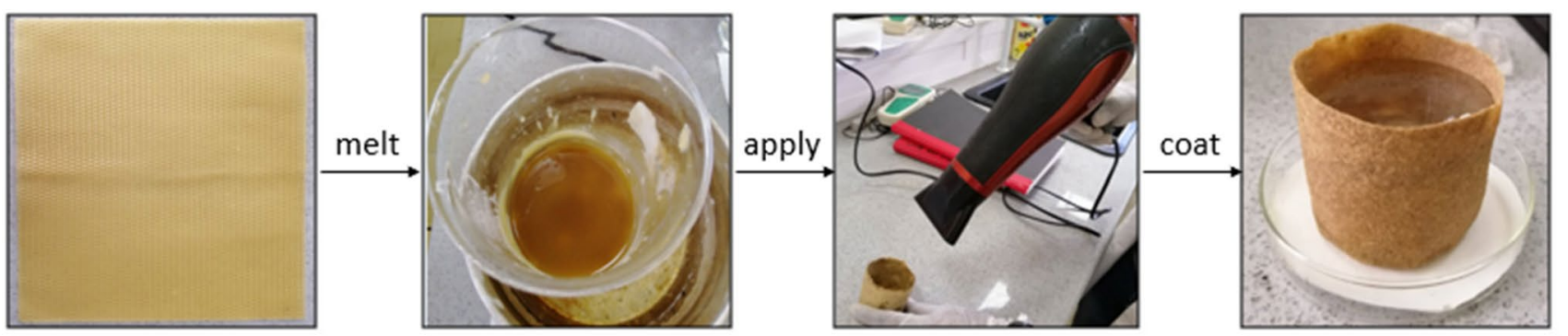

Fig. 3 Beeswax coating of composite paper cup

Table 2 Word codes assigned to each property of a molded cup to check for conformance

Table 3 Scores allocated to different grades of texture and number of cracks

\begin{tabular}{lll}
\hline & $\begin{array}{l}\text { If cup is conformant to standard, } \\
\text { report as }\end{array}$ & $\begin{array}{l}\text { If cup is not conform- } \\
\text { ant to standard, report } \\
\text { as }\end{array}$ \\
\hline $\begin{array}{lll}\text { Color } & \text { Normal } & \text { Not normal } \\
\text { Stability of base cup } & \text { Smooth, tidy and neat } & \begin{array}{l}\text { Not smooth, tidy and } \\
\text { neat }\end{array} \\
\text { Grease/dirt/dust } & \text { Stable } & \text { Not stable }\end{array}$ \\
\hline
\end{tabular}

\begin{tabular}{lll}
\hline Scores assigned & Texture & Cracks \\
\hline 1 & Cup is very smooth & Cup has no cracks \\
2 & Cup is more smooth than rough & Cup has only one crack \\
3 & Cup is more rough than smooth & Cup has two cracks \\
4 & Cup is very rough & Cup has more than two cracks \\
5 & - & Cup is all cracked up
\end{tabular}

Table 4 Appearance and structure test results

\begin{tabular}{|c|c|c|c|c|c|c|}
\hline Cup sample & Color & Grease/dirt/dust & Stability of base & Edge of cup & Texture & Cracks \\
\hline Control & Normal & Absent & Stable & Smooth, tidy and clean & 1 & 1 \\
\hline \multicolumn{7}{|c|}{ Hemp:pineapple peels composite } \\
\hline $100 \%$ pineapple peels & Normal & Absent & Stable & Smooth, tidy and clean & 1 & 5 \\
\hline $20: 80$ & Normal & Absent & Stable & Smooth, tidy and clean & 1 & 1 \\
\hline $40: 60$ & Normal & Absent & Stable & Smooth, tidy and clean & 2 & 1 \\
\hline $60: 40$ & Normal & Absent & Stable & Smooth, tidy and clean & 2 & 1 \\
\hline $80: 20$ & Normal & Absent & Stable & Smooth, tidy and clean & 4 & 4 \\
\hline \multicolumn{7}{|c|}{ Hemp:orange peels composite } \\
\hline $100 \%$ orange peels & Normal & Absent & Stable & Smooth, tidy and clean & 1 & 5 \\
\hline $20: 80$ & Normal & Absent & Stable & Smooth, tidy and clean & 1 & 5 \\
\hline $40: 60$ & Normal & Absent & Stable & Smooth, tidy and clean & 2 & 1 \\
\hline $60: 40$ & Normal & Absent & Stable & Smooth, tidy and clean & 3 & 1 \\
\hline $80: 20$ & Normal & Absent & Stable & Smooth, tidy and clean & 4 & 1 \\
\hline
\end{tabular}

The results for the appearance and structure tests are given in Table 4.

As per the GB 18006 (2008) standard [16], the color of the cup should be normal, with no discoloration or stains except for decoration purposes. The control cup had colored patterns for decoration purposes, and hence, its color was considered normal. All molded composite cups had a normal, uniform color with no stains. The color of

\section{SN Applied Sciences}


paper cups from both pineapple and orange peels composite was also found to be significantly paler as compared to the original color of the peels and hemp leaves. This can be explained by the degradation of pigments found in the peels at the high temperature as well as the removal of lignin during the pulping process. Similar phenomenon was observed by Park et al. [26], who reported the color of composite boards from cranberry pomace to change due to degradation of red pigments at high molding temperature.

No grease, dirt or dust was present on any cup, and all cups had a stable base. The edges of the cups were trimmed so that they were smooth, tidy and clean. Hence, there was no problem with regard to the initial visual appearance of the paper cups. In terms of texture, however, it was observed that the general trend was a smoother cup with increasing percentage of pineapple and orange peels from 20 to $80 \%$. This might be because the fruits' pulps were smaller in size, which upon blending, became finer, thereby resulting in a smoother cup. The Mauritian hemp pulp, however, was coarser. Hence, as its percentage in the mix ratio increased, the cup became less smooth.

This observation was in line with that of Gouw et al. [10], who reported coarser packaging board because of coarser newspaper fibers as compared to fruit pomace fibers. lewkittayakorn et al. [27] also observed that a coarse texture was obtained with pineapple leaves pulp with leaf residues showing even after compression molding. Increasing the cooking time to $180 \mathrm{~min}$ chemical pulping time would produce paper with fine structure and no residues of pineapple leaves. However, in this study, $90 \mathrm{~min}$ was sufficient to obtain fine fruit peels fibers for a smooth texture without compression, which can be advantageous in terms of processing parameters and heat energy requirement on an industrial scale.

With increasing peels pulp percentage, however, the number of cracks increased for the orange peels. This is because the orange peels fibers are shorter and weaker and tend to rip apart during the drying process. The paper cups cracked at $80 \%$ and $100 \%$ orange peels. For the pineapple peels, the cup containing the highest percentage of hemp pulp ( $80 \%$ hemp) cracked despite the hemp fibers are stronger than the orange peel and pineapple peel fiber.

This is because the hemp fibers were grinded, thereby shortening the length. Since short fibers are weaker than long fibers $[23,28-30]$, the hemp fibers in the mix ratio $80: 20$ could not bind properly. There were also more voids in between the fibers since less finer pineapple fibers were present to interlock with the hemp fibers. Since paper cups should contain no cracks as per the GB 18006 (2008) standard [16], those having cracks were considered unfit for purpose and were therefore eliminated. They were not used for subsequent tests, which require cup samples having no cracks.

\subsection{Drop test}

Sample cups with no cracks were dropped from a height of $0.8 \mathrm{~m}$ and were thereafter analyzed for cracks or splits after impacting on a level cement floor as given in Table 5 .

All molded cups remained intact, with no deformation, cracks or split after the drop test as the control cup, except the $60: 40$ and 80:20 orange composite cups. The drop test gives an early indication of the strength properties of the molded cups. Those which cracked after the drop test shows that no big force was necessary to rupture the bonds between the lignocellulosic fibers. Since the GB 18006 (2008) standard [16] states that the cups should not crack after the drop test to be fit for purpose, they were therefore viewed as not strong enough to be used as drinking cups. These two composite cups were therefore eliminated.

\subsection{Weight load test}

Those cups conformant to the drop test were then subjected to a $3 \mathrm{~kg}$ load for the weight load test as given in Table 6 , where $w=$ the variation rate of the weight load of the sample (\%), $h_{0}=$ the height before weight is loaded $(\mathrm{mm}), h=$ the height after weight is loaded $(\mathrm{mm})$.

This test assesses the load-bearing performance of the cups, that is, the ability of the cups to hold the liquid load while being held in the hands of the user without being subjected to any deformation.

The variation rate of weight load, which represents the change in height of the cup due to compression by the $3 \mathrm{~kg}$ load, decreased to $0 \%$ at $60 \%$ pineapple peels fiber and increased to a maximum of $2.72 \%$ at $80 \%$ pineapple

Table 5 Crack analysis of composite cups after drop test

\begin{tabular}{lll}
\hline Cup sample & $\begin{array}{l}\text { Cup sample } \\
\text { remained intact }\end{array}$ & $\begin{array}{l}\text { Cup sample } \\
\text { cracked or } \\
\text { split }\end{array}$ \\
\hline Control & $\checkmark$ & \\
Hemp:pineapple peels composite & & \\
20:80 & $\checkmark$ & \\
40:60 & $\checkmark$ & \\
60:40 & $\checkmark$ & $\checkmark$ \\
Hemp:orange peels composite & & $\checkmark$ \\
40:60 & $\checkmark$ & \\
60:40 & & \\
80:20 & & \\
\end{tabular}


Table 6 Variation rate of weight load test results on molded cup samples

\begin{tabular}{|c|c|c|c|c|c|}
\hline & \multirow[t]{2}{*}{ Control cup } & \multicolumn{3}{|c|}{ Hemp:pineapple peels composite cups } & \multirow{2}{*}{$\begin{array}{l}\text { Hemp:orange } \\
\text { peels composite } \\
\text { cup } \\
40: 60\end{array}$} \\
\hline & & $20: 80$ & $40: 60$ & $60: 40$ & \\
\hline$<h_{0}>(\mathrm{mm})$ & 87.00 & 37.97 & 44.07 & 66.0 & 42.9 \\
\hline$<h>(\mathrm{mm})$ & 87.00 & 36.93 & 44.07 & 65.03 & 41.77 \\
\hline$<w>(\%)$ & $0.00 \pm 0.00$ & $2.72 \pm 0.66$ & $0.00 \pm 0.00$ & $1.46 \pm 0.09$ & $2.64 \pm 0.36$ \\
\hline
\end{tabular}

Table 7 Average thickness of cup specimen which passed the drop and weight load tests

\begin{tabular}{ll}
\hline Sample & Average thickness (mm) \\
\hline Control cup & $0.372 \pm 0.008$ \\
Hemp:pineapple peels composite cups & \\
$20: 80$ & $1.124 \pm 0.130$ \\
$40: 60$ & $1.416 \pm 0.158$ \\
$60: 40$ & $1.029 \pm 0.120$ \\
Hemp:orange peels composite cups & \\
40:60 & $1.965 \pm 0.207$ \\
\hline
\end{tabular}

peels fiber (Table 6). This might imply that the 60:40 hemp:pineapple composite cup provides the best combination of the finer pineapple and coarser hemp fibers, which binds together sufficiently to result in a highstrength, high-bulk-density paper cup. The 60:40 mix ratio had the same variation rate of weight load of $0 \%$ as the control cup, whereas the remaining two compositions were subjected to a significant increase in variation rate of weight load. In order to justify the ultimate cup composition, however, the tensile and burst strength tests were performed.

\subsection{Thickness determination}

The average thickness of cup specimens conforming to the drop and weight load tests is given in Table 7.

The composite cups were observed to have a higher average value for thickness (all above $1.00 \mathrm{~mm}$ ) than the control cup, with the pineapple peels composite cups have a thickness value closer to the control cup. The cup molding process involved no compression of the fibers, as a result of which there was no significant degree of compaction. The control cup, on the other part, was well compacted in the form of sheets prior to making the cup. Hence, the thickness of the cup specimens was higher. This observation is supported by the study Saxena et al. [31], who found that the maximum thickness of paper bottle formed through vacuum molding was $1.969 \mathrm{~mm}$.

The thickness of the orange peels composite cups was found to be higher than that of the pineapple peels composite. This implies that more pulp was required to form one cup of the same capacity using the orange peels composite than the pineapple peels composite. Using the compression molding technique would result in a lower thickness for the same amount of pulp used since the bulk density would have increased due to compaction. Nevertheless, while compression molding resolves the problem of uneven fiber distribution and hence, uneven thickness, the study conducted by lewkittayakorn et al. [27] revealed that more pulp would be required to obtain a compressed product without cracks as compared to a vacuum-molded one. This may have implications on the cost of raw material needed. As such, improving the vacuum molding process to enable the obtention of a product of even thickness could be a potential area of study.

\subsection{Burst strength test}

The bursting strength test indicates the ability of the paper cup to resist a rupture force applied perpendicular to it. It also provides an indication of the distribution matrix of the fibers within the paper cup. The distribution of fibers is usually affected by the fiber quality and length, addition of surface additives, blending time and the method of preparation [32]. The values of burst index (B) of the paper cups produced are recorded in Table 8.

The burst index reached a maximum at $60 \%$ pineapple peels fiber (Table 8), indicating that the addition of $40 \%$ hemp in the pulp mix produced the most burst-resistant paper cup, which needs $75.2 \mathrm{kPa}$ to burst. The burst index increased as the percentage of pineapple fiber increased from 40 to $60 \%$, but decreased significantly at $80 \%$ pineapple peels fiber. This decrease might be attributed to the uneven distribution of the pineapple peel fibers in the paper cup during the molding process or lower bonding strength between the fibers. The burst index for the orange peels composite cup was lowest compared to all pineapple peels composites, thereby implying that a much smaller pressure is needed to burst the hemp to orange composite cup specimen. For the same mix ratio of $40 \%$ peels and $60 \%$ hemp, the burst index was $0.08 \mathrm{kPa} \mathrm{m}^{2} / \mathrm{g}$ using orange peels, while it was $0.25 \mathrm{kPa} . \mathrm{m}^{2} / \mathrm{g}$ using pineapple peels. This reveals that the orange peels fibers have 
Table 8 Recorded pressure values for burst test and corresponding burst index $B$

\begin{tabular}{|c|c|c|c|c|c|}
\hline & \multirow[t]{2}{*}{ Control } & \multicolumn{3}{|c|}{$\begin{array}{l}\text { Ratio of hemp:pineapple } \\
\text { peels composite cup }\end{array}$} & \multirow{2}{*}{$\begin{array}{l}\text { Ratio of } \\
\text { hemp:orange } \\
\text { peels } \\
40: 60\end{array}$} \\
\hline & & $20: 80$ & $40: 60$ & $60: 40$ & \\
\hline No of turns & 16 & 14 & 15 & 13 & 13 \\
\hline \multirow[t]{3}{*}{$P_{1}\left(\mathrm{~kg} / \mathrm{cm}^{2}\right)$} & 5.40 & 1.00 & 1.30 & 1.20 & 0.50 \\
\hline & 5.80 & 1.00 & 1.20 & 1.20 & 0.75 \\
\hline & 5.70 & 1.00 & 1.30 & 0.75 & 0.50 \\
\hline$P_{2}\left(\mathrm{~kg} / \mathrm{cm}^{2}\right)$ & 1.20 & 0.75 & 0.50 & 0.25 & 0.25 \\
\hline \multirow[t]{3}{*}{$P\left(\mathrm{~kg} / \mathrm{cm}^{2}\right)$} & 4.20 & 0.25 & 0.80 & 0.95 & 0.25 \\
\hline & 4.60 & 0.25 & 0.70 & 0.95 & 0.50 \\
\hline & 4.50 & 0.25 & 0.80 & 0.50 & 0.25 \\
\hline$<P>\left(\mathrm{kg} / \mathrm{cm}^{2}\right)$ & 4.43 & 0.25 & 0.77 & 0.80 & 0.33 \\
\hline$p(\mathrm{kPa})$ & 434.76 & 24.52 & 75.18 & 78.45 & 32.69 \\
\hline$g\left(\mathrm{~g} / \mathrm{m}^{2}\right)$ & 228.68 & 269.36 & 304.69 & 479.34 & 378.79 \\
\hline$B\left(\mathrm{kPa} \mathrm{m}^{2} / \mathrm{g}\right)$ & 1.90 & 0.09 & 0.25 & 0.16 & 0.08 \\
\hline
\end{tabular}

lower fiber and inter-fiber bonding strength than the pineapple peels fibers.

Therefore, inter-fiber bonding, which was controlled by the pulp density and porosity, influences the paper cups strength. This explains the immediate fracture of the material after maximum bursting strength instead of undergoing further plastic deformation with lower stress rate. The crack formation also does not exhibit any specific direction [33]. In addition, the fiber quality and length, which depends on its preparation method, pre-treatment options (grinding or refining) and/or blending time, affect the burst strength of the sample since shorter fiber length and lower fiber quality results in a lower burst index and vice versa.

\subsection{Tensile strength test}

The tensile strength test indicates the ability of the cup sample to resist a rupture force applied parallel to it. The mean tensile properties obtained for each test specimen (Table 9) were ultimately used to calculate the tensile index.

The trend of tensile index was observed to be similar to that of the bursting index with respect to the percentage of pineapple peels fiber (Fig. 4). The tensile index reached a maximum at $60 \%$ pineapple peels fiber. The maximum tensile index may be the result of stronger interfacial bonding, lower lignin content, higher cellulose content, better proportion of hemp-pineapple fiber mix and lower micro-fibrillar angle present in the pineapple fibers [22].

The tensile index increased as the percentage of pineapple fiber increased from 40 to $60 \%$, but decreased significantly at $80 \%$ pineapple peels fiber. This decrease might be attributed to the irregular scattering of the pineapple peel fibers in the paper cup during the molding process or lower bonding strength between the fibers.

The tensile index for the orange peels composite cup was lower than all the pineapple peels composites, except for the 80:20 hemp-pineapple peels one. This implies that the 40:60 hemp-orange peels composite has a higher fiber and bonding strength than the 80:20 hemp-pineapple peels cup. For the same mix ratio of $40 \%$ peels and $60 \%$ hemp, the tensile index was $0.13 \mathrm{Nm} / \mathrm{g}$ using orange peels, while it was 3.30 using pineapple peels. This reveals that the orange peels fibers have lower fiber and bonding strength than the pineapple peels fibers at this mix ratio. The tensile index of the 40:60 hemp-pineapple peels composite was also found to be roughly 8 times lower than the control cup, which has a tensile index of $26.1 \mathrm{Nm} / \mathrm{g}$.
Table 9 Mean tensile properties of paper cup specimen

\begin{tabular}{lccccc}
\hline & Control & \multicolumn{2}{l}{$\begin{array}{l}\text { Ratio of hemp:pineapple peels com- } \\
\text { posite cup }\end{array}$} & $\begin{array}{l}\text { Ratio of } \\
\text { hemp:orange } \\
\text { peels }\end{array}$ \\
\cline { 3 - 5 } & & $20: 80$ & $40: 60$ & $60: 40$ & $40: 60$ \\
\hline Grammage, $g\left(\mathrm{~g} / \mathrm{m}^{2}\right)$ & 228.68 & 269.36 & 304.69 & 479.34 & 378.79 \\
Elongation at break $(\mathrm{mm})$ & 5.23 & 0.60 & 0.61 & 1.31 & 2.67 \\
Elongation at peak $(\mathrm{mm})$ & 5.16 & 0.53 & 0.57 & 1.06 & 0.89 \\
Force at break (N) & 145.50 & 9.81 & 22.99 & 0.64 & 0.11 \\
Force at peak (N) & 149.30 & 11.48 & 25.14 & 1.20 & 1.20 \\
Time to failure (s) & 63.02 & 7.26 & 7.35 & 15.83 & 32.16 \\
Strain at break (\%) & 3.49 & 0.40 & 0.41 & 0.88 & 1.78 \\
Stress at break (N/mm $\left.{ }^{2}\right)$ & 15.73 & 0.36 & 0.85 & 0.02 & 0.01 \\
Young's modulus $\left(\mathrm{N} / \mathrm{mm}^{2}\right)$ & 1092.35 & 148.53 & 284.24 & 3.87 & 28.26 \\
Width of strip (m) & 0.025 & 0.025 & 0.025 & 0.025 & 0.025 \\
Tensile index, $\mathrm{I}(\mathrm{Nm} / \mathrm{g})$ & 26.12 & 1.70 & 3.30 & 0.01 & 0.13 \\
\hline
\end{tabular}


Fig. 4 Test sequence to find the ultimate cup composition

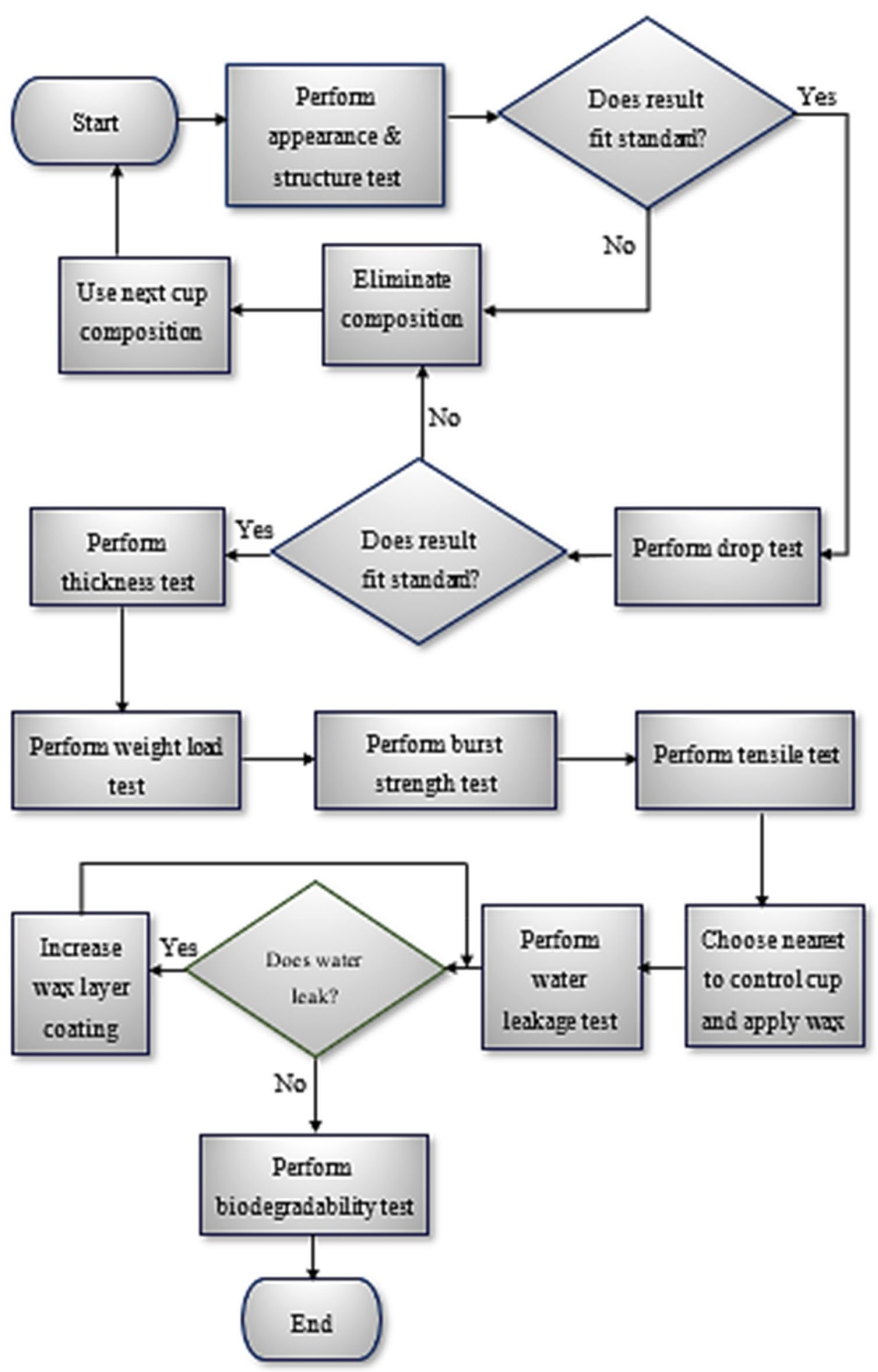


Fig. 5 100\% pineapple peels paper cup (left) and 100\% orange peels paper cup (right)
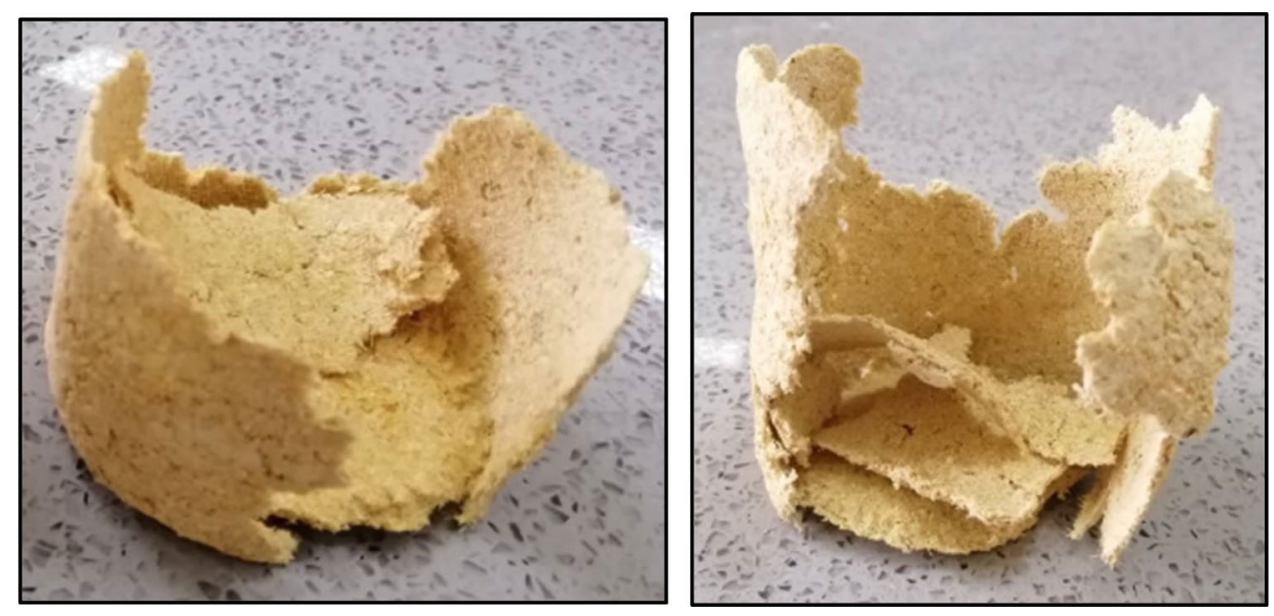

The 40:60 hemp-pineapple peels composite cup therefore provided the best combination of variation rate of weight load, burst and tensile strength properties, which were nearer to those of the control cup. It was thus chosen as the ultimate cup composition for waterproof coating.

\subsection{Water leakage test}

In order for the paper cup to be fit for purpose, the waterproof material should be such that it prevents water or any other liquid from leaking. Therefore, the beeswax coating thickness was varied to test the water resistance of the cup.

The logical trend observed from Fig. 5 is an increase in the time the cup takes to leak with increasing beeswax coating thickness. At low thickness coating, it was observed that the amount of lipids in beeswax was not enough to prevent the water from penetrating the fiber network and the paper cup would leak. At $0.7 \mathrm{~mm}$ coating thickness, the cup held water at the time specified by the GB 18006 (2008) standard (30 min). The thickness of beeswax coating was thus limited to $0.7 \mathrm{~mm}$ since beyond this value, the wax remained as solidified lumps on the cup
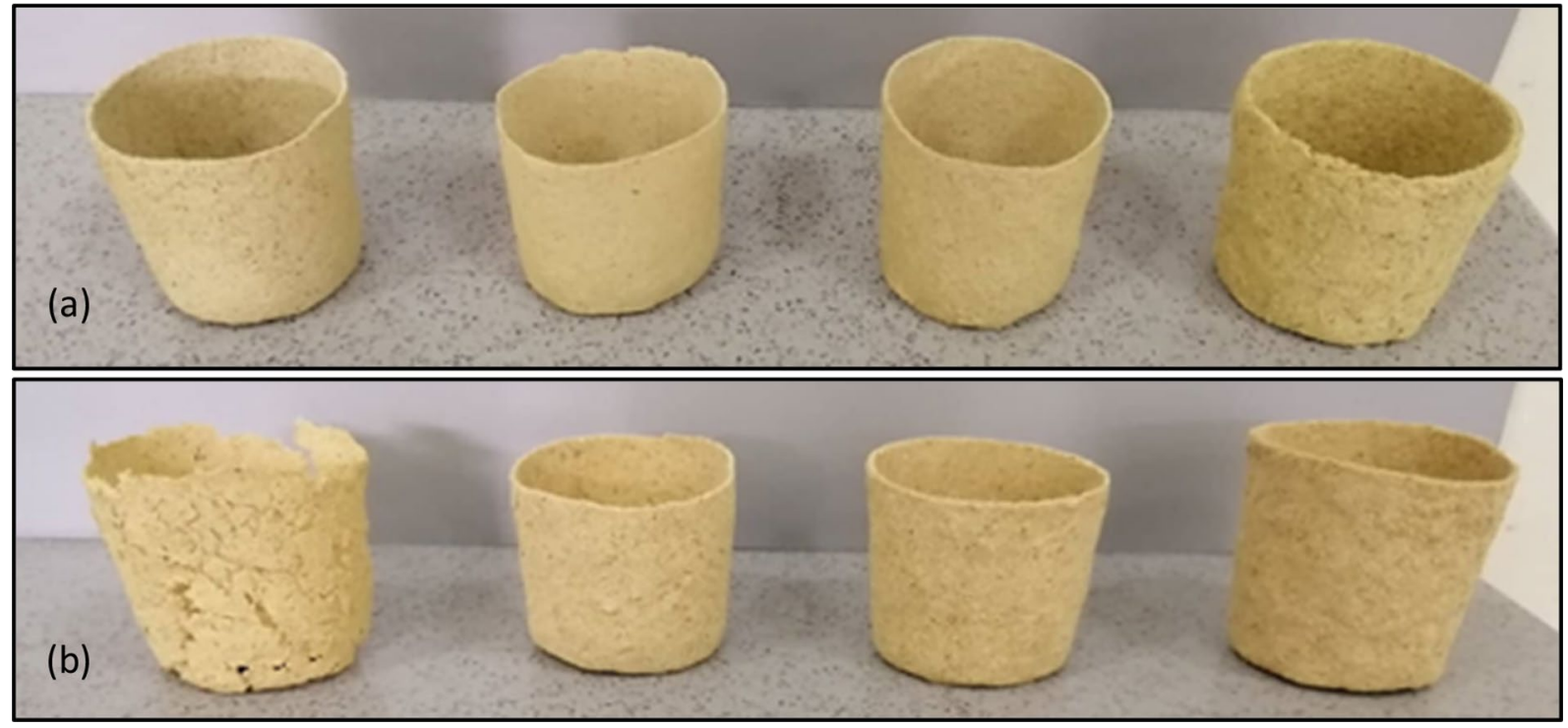

Fig. 6 a Hemp:pineapple peels composite paper cups and $\mathbf{b}$ hemp-orange peels composite paper cups in the ratio 20:80, 40:60, 60:40 and 80:20 (from left to right) 
surface. This is because the cup was already saturated with the melted wax, which filled all pores of the cup.

While biodegradable paper cups are usually coated with polylactic acid as substitute to polyethylene for waterproofing [34], using beeswax presents several advantages. Beeswax is considered food grade material since it is used as additives in pharmaceuticals and foods [27]. It is also rich in lipids, which can enhance water repellence in a coating due to their strong hydrophobicity [27]. It was in fact more water resistant than the sodium alginate-gellan composite used by Zhang et al. [35] to bio-coat paper cups for hot drinks, that has calcium ions as a crosslinking agent and plasticizer to enhance water resistance. However, beeswax does not contribute to added mechanical strength $[27,35]$ and cannot sustain hot liquids due to its low melting point of $60-70^{\circ} \mathrm{C}$ [36]. As such, the coating was applied to both sides of the cup since the latter is intended to be used as a cold cup.

\subsection{Biodegradability test results}

The rate at which a substance biodegrade depends on several factors, including moisture content, temperature, nutrients and microorganisms content of the medium in which it is buried, as well as the size, surface area and inherent biodegradability potential of the substance itself. In this study, the biodegradation of $5 \times 5 \mathrm{~cm}$ samples occurred in two different environments, namely active soil and damp sand, at a measured average temperature of $34^{\circ} \mathrm{C}$ and average $\mathrm{pH}$ of 7.4 for the seawater used to
Fig. 7 Variation of mean burst and tensile indexes with pineapple peels fiber
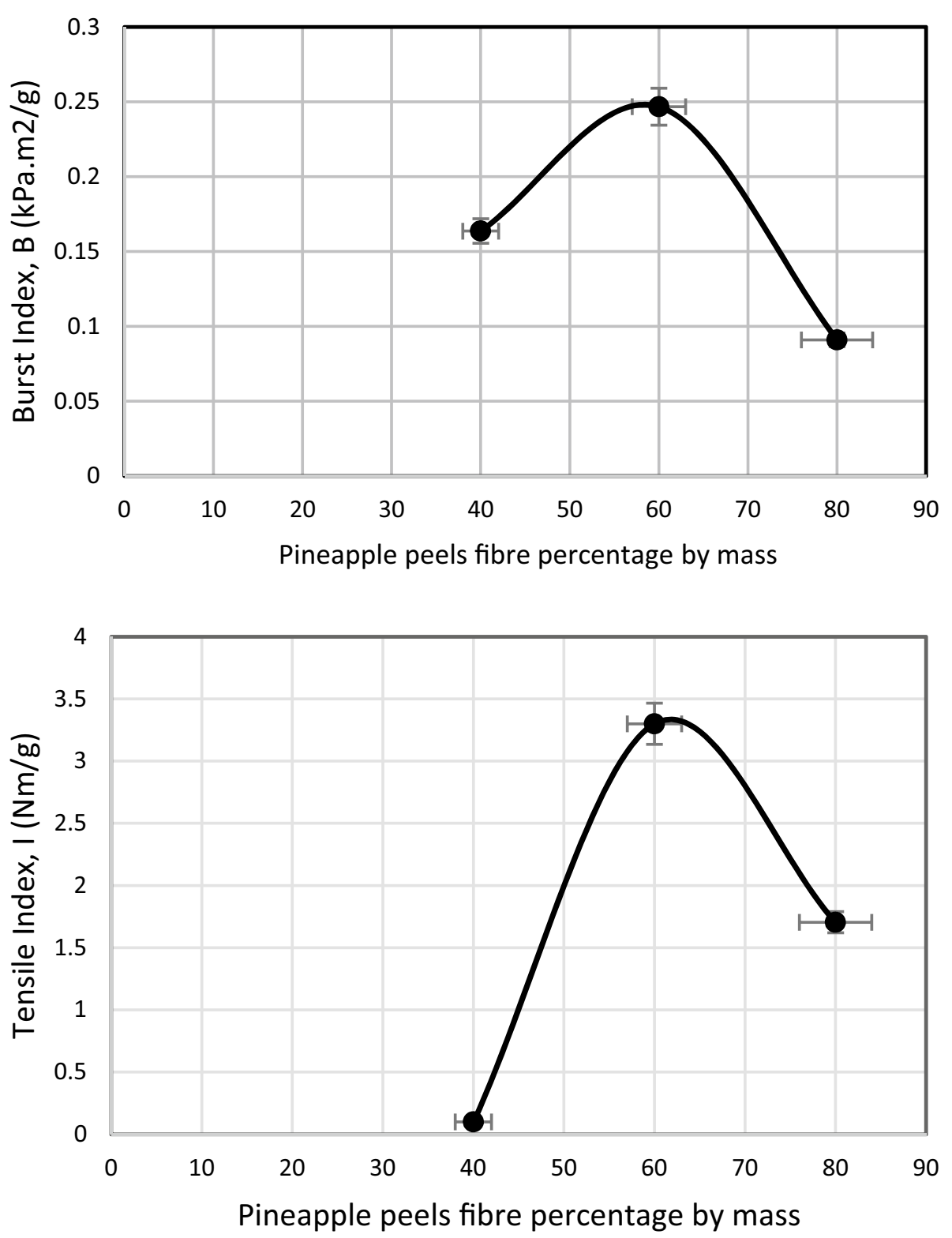
keep the sand medium damp. The decrease in mass of the samples after each week was recorded and thereafter plotted as in Fig. 6.

The control cup is observed to biodegrade at a slower rate as compared to the composite cup in both environments. The control cup has a polyethylene coating which delays the biodegradation process of the paper part of the cup. Since the coating is on one side only, the surface area exposed to the soil and sand environment for biodegradation is one-sided. After the 4 weeks period, the polyethylene film detached itself from the paper cup exposed to the damp sand environment. The film was, however, intact after 4 weeks, which implies that the film will take a much longer time to degrade, potentially into microplastics. The rate of biodegradation of the paper control cup is therefore expected to increase after the 4 weeks period (Figs. 7, 8).

The wax-coated hemp-pineapple composite cup, on the other part, was subjected to a greater loss in mass, since both the waterproof coating and fiber making up the cup are biodegradable. In this respect, it can be inferred that using the composite cup will impact negatively the environment to a lesser extent than when using the control cup. The composite cup disappeared after 5 weeks in soil, whereas traces remained in the damp sand until after 6 weeks. As observed from Fig. 9, the rate of biodegradation of the composite cup is greater in soil than that in sand. This is because the nutrients content required by microorganisms to function was lower in sand than in the
Fig. 8 Variation of water resistance of 40:60 hemp-pineapple peels cup with coating thickness
Fig. 9 Decrease in mass of cup specimen as it biodegrades for a period of 4 weeks
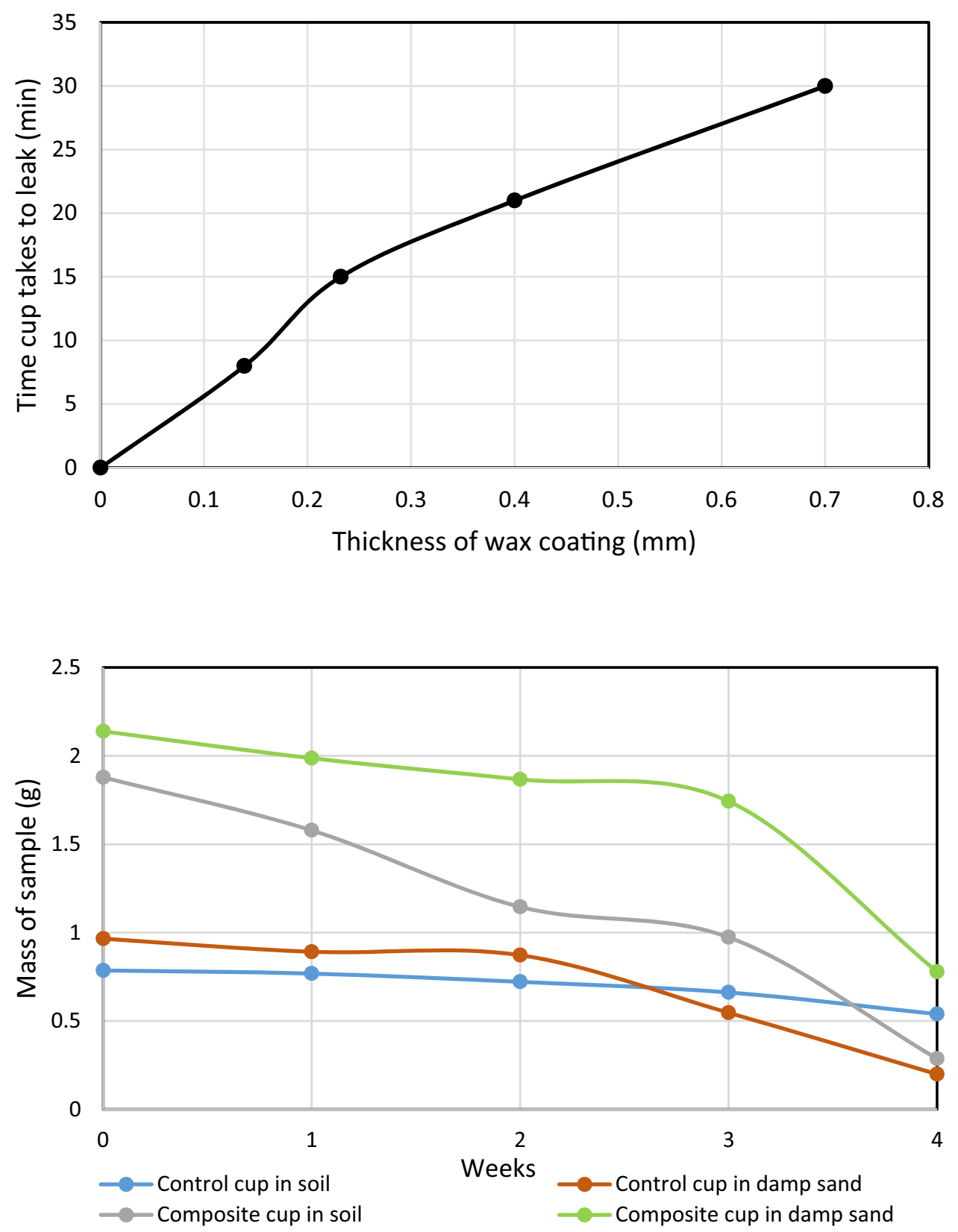
active soil, considering that the temperature and moisture were almost same for both environments since they were subjected to the same weather conditions.

\section{Conclusion}

This study demonstrated that fiber extraction from fruit peel wastes and hemp leaves, which are feedstocks otherwise disposed of as agricultural waste in the landfill, and utilizing the transformed fibers in the production of an eco-friendly, biodegradable disposable paper cup is a feasible option. Satisfactory experimental results were observed with the different paper cup admixtures, considering the fact that no binder or filler materials were used to favor the bonding process. The production of paper cups from agro-waste using less water, energy and raw materials could therefore be a means of boosting the economy of a country by transforming these wastes into added-value products, while minimizing deforestation and the amount of waste reaching the landfill. The obtained experimental data can provide prospects on utilization of other types of biomass for the production of single use biodegradable cups or plates that have similar properties to fibers present in pineapple, orange peels and Mauritian hemp. Furthermore, this research work opens prospects for further research with respect to improving the properties of these paper cups by considering alternative waterproof coatings that enhance the mechanical strength of the paper cups as well as performing other studies related to paper cups to evaluate their service performances for further comparisons.

\section{Compliance with ethical standards}

Conflict of interest The authors declare that they have no competing interests.

\section{References}

1. Wold J (2019) Global Paper Cups market overview 2019: growth, demand and forecast research report to 2024. http://www.resea rz.com/global-paper-cups-market-report?fbclid=IwAROS3aar 784I2GhvgifsDWA3DpEKvJ-vFZ4HOCfE-sItpiTdHy1LV_r4nx8. Accessed 23 Dec 2018

2. Shen $M$, Song $B$, Zeng $G$, Zhang $Y$, Huang $W$, Wen $X$, Tand $W$ (2020) Are biodegradable plastics a promising solution to solve the global plastic pollution? Environ Pollut 263:1-7. https://doi. org/10.1016/j.envpol.2020.114469

3. Gabbatiss J (2018) Disposable coffee cups: How big a problem are they for the environment? https://www.independent.co.uk/ environment/disposable-coffee-cups-how-big-problem-envir onment-landfill-recycling-incinerate-export-rubbish-a8142381. html. Accessed 01 Sept 2018

4. Marichelvam MK, Jawaid M, Asim M (2019) Corn and rice starchbased bio-plastics as alternative packaging materials. Fibers 7:1-14. https://doi.org/10.3390/fib7040032

5. Oakes K (2019) "Green" alternatives to throwaway plastics don't always break down in sea water. But could they help to fix our food waste problem? https://www.bbc.com/future/artic le/20191030-why-biodegradables-wont-solve-the-plastic-crisi s. Accessed 05 May 2020

6. Pavlovskay NE, Gorkova IV, Gagarina IN, Gavrilova AY (2020) Creation of new polymer composite bioplastics to produce disposable tableware based on starch. IOP Conf Ser: Earth Environ Sci 422:1-7. https://doi.org/10.1088/17551315/422/1/012120/pdf

7. Liu BF, Liu MD, Jin P, Zhong YX (2020) Study of pulping technology on disposable tableware using withered leaves as raw material. IOP Conf Ser: Mater Sci Eng 711:1-8. https:// doi.org/10.1088/1757-899X/711/1/012056/pdf

8. Hanley J, Hermann R, Hudak T, Lewis R, Ross P (2019) A biodegradable alternative to the single-use cup. Dissertation, Worcester Polytechnic Institute

9. Curling SF, Laflina N, Daviesa GM, Ormondroyd GA, Elias RM (2017) Feasibility of using straw in a strong, thin, pulp moulded packaging material. Ind Crops Prod 97:395-400. https://doi.org/10.1016/j.indcrop.2016.12.042

10. Gouw VP, Jung J, Simonsen J, Zhao Y (2017) Fruit pomace as a source of alternative fibers and cellulose nanofiber as reinforcement agent to create molded pulp packaging boards. Compos Part A. https://doi.org/10.1016/j.composites a.2017.04.007

11. ASTM E 1756-08 (2015) Standard test method for determination of total solids in biomass. https://www.scribd.com/docum ent/355268125/E-1756-08-2015. Accessed 21 Dec 2018

12. ASTM E 1755-01 (2015) Standard test method for ash in biomass. https://www.scribd.com/document/355268116/E-175501-2015. Accessed 21 Dec 2018

13. Soest VJP (1963) Use of detergents in the analysis of fibrous feeds. II. A rapid method for the determination of fiber and lignin. J Assoc Off Anal Chem 46:829-835

14. Soest VJP, Wine RH (1967) Use of detergents in the analysis of fibrous feeds. IV. Determination of plant cell-wall constituents. J Assoc Off Anal Chem 50:50-55

15. Sibaly S, Jeetah P (2017) Production of paper from pineapple leaves. J Environ Chem Eng 5:5978-5986. https://doi. org/10.1016/j.jece.2017.11.026

16. GB 18006 (2008) General requirement of disposable plastic tableware. https://members.wto.org/crnattachments/2009/ TBT/CHN/09_0814_00_et.pdf. Accessed 27 Dec 2018

17. TAPPI T403 OM (1997) Bursting strength of paper. http://grayh all.co.uk/BeloitResearch/tappi/t403.pdf. Accessed 30 Sept 2018

18. TAPPI T494 OM (2006) Tensile properties of paper and paperboard. https://wenku.baidu.com/view/2101331ffe4733687e21 aa6a.html?re=view. Accessed 30 Sept 2018

19. Tosin M, Siotto M, Weber M, Lott C, Innocenti FD (2012) Laboratory test methods to determine the degradation of plastics in marine environmental conditions. Front Microbiol 3:1-9. https ://doi.org/10.3389/fmicb.2012.00225

20. Rosario L, Dell E (2010) AC 2010-593: biodegradability of plastics testing in an undergraduate materials laboratory course. https://www.google.com/url?sa=t\&rct=j\&q=\&esrc=s\&sourc $\mathrm{e}=$ web\&cd=\&ved=2ahUKEwjggr_o4L3qAhXsAGMBHRAfAZw QFjAAegQIBRAB\&url=https\%3A\%2F\%2Fpeer.asee.org\%2Fbio degradability-of-plastics-testing-in-an-undergraduate-mater ials-laboratory-course.pdf\&usg=AOvVaw33u2ZFpIKC7j8PPdGzZ OL6. Accessed 30 Sept 2018 
21. Brink M, Achigan-Dako EG (2012) Plant resources of Tropical Africa 16: Fibres. PROTA Foundation, The Netherlands

22. Manimaran $P$, Senthamaraikannan $P$, Sanjay MR, Marichelvam MK, Jawaid M (2017) Study on characterization of Furcraea foetida new natural fiber as composite reinforcement for lightweight applications. Carbohydr Polym 181:650-658. https://doi.org/10.1016/j.carbpol.2017.11.099

23. Reddy GS (2015) Eco-friendly production of paper products. Int J Chem Concepts 1:72-80

24. Buchwald R, Breed MD, Greenberg AR (2008) The thermal properties of beeswaxes: unexpected findings. J Exp Biol 211:121-127. https://doi.org/10.1242/jeb.007583

25. Abdel-Aal MA (2013) Effect of cooking time, active alkali concentration and refining process on the pulping and papermaking properties of buttonwood residues (Conocarpus erectus L.). World Appl Sci J 27:1-9

26. Park S, Jiang Y, Simonsen J, Zhao Y (2010) Feasibility of creating compression-molded biocomposite boards from berry fruit pomaces. J Appl Polym Sci 115:127-136. https://doi. org/10.1002/app.30951

27. lewkittayakorn J, Khunthongkaew $P$, Wongnoipla $Y$, Kaewtatip K, Suybangdum P, Sopajarn A (2020) Biodegradable plates made of pineapple leaf pulp with bio coatings to improve water resistance. J Mater Res Technol. https://doi.org/10.1016/j. jmrt.2020.03.023

28. Ververis C, Georghiou K, Christodoulakis N, Santas P, Santas R (2003) Fiber dimensions, lignin and cellulose content of various plant materials and their suitability for paper production. Ind Crop Prod 19:245-254. https://doi.org/10.1016/j.indcr op.2003.10.006

29. Jadhav AC, Pandit P, Gayatri TN, Chavan PP, Jadhav NC (2019) Production of green composites from various sustainable raw materials. In: Muthu SS (ed) Green composites. Springer, Singapore, pp 1-24
30. Kaur H, Dutt D, Tyagi CH (2010) Optimization of soda pulping process of lignocellulosic residues of lemon and sofia grasses produced after steam distillation. BioResources 6:103-120

31. Saxena P, Bissaco G, Gundlach C, Dahl VA, Trinderup CH, Dahl $A B$ (2019) Process characterization for molding of paper bottles using computed tomography and structure tensor analysis. In: 9th Conference on industrial computed tomography

32. Ramdhonee A, Jeetah P (2017) Production of wrapping paper from banana fibres. J Environ Chem Eng. https://doi. org/10.1016/j.jece.2017.08.011

33. Masni-azian A, Choudhury IA, Sihombing H, Yuhazri MY (2012) Tensile properties evaluation of paper pulp packaging at different sections and orientations on the egg tray. Adv Mater Res 626:542-546. https://doi.org/10.4028/www.scientific.net/ AMR.626.542

34. Scitech Europa (2019) Paper or plastic? The take-over of the paper cup. https://www.scitecheuropa.eu/paper-or-plastic-thetake-over-of-the-paper-cup/98275/. Accessed 17 May 2020

35. Zhang N, Xu J, Gao X, Fu X, Zheng D (2017) Factors affecting water resistance of alginate/gellan blend films on paper cups for hot drinks. Carbohydr Polym. https://doi.org/10.1016/j.carbp ol.2016.08.101

36. Kameda T (2004) Molecular structure of crude beeswax studied by solid-state 13C NMR. J Insect Sci. https://doi.org/10.1093/ jis/4.1.29

Publisher's Note Springer Nature remains neutral with regard to jurisdictional claims in published maps and institutional affiliations. 